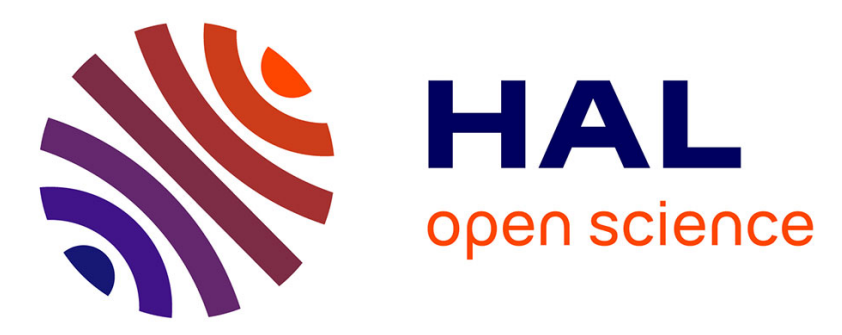

\title{
A conditioned reinforcer did not help to maintain an operant conditioning in the absence of a primary reinforcer in horses
}

Léa Lansade, Ludovic Calandreau

\section{- To cite this version:}

Léa Lansade, Ludovic Calandreau. A conditioned reinforcer did not help to maintain an operant conditioning in the absence of a primary reinforcer in horses. Behavioural Processes, 2018, 146, pp.6163. 10.1016/j.beproc.2017.11.012 . hal-02621915

\section{HAL Id: hal-02621915 \\ https://hal.inrae.fr/hal-02621915}

Submitted on 26 May 2020

HAL is a multi-disciplinary open access archive for the deposit and dissemination of scientific research documents, whether they are published or not. The documents may come from teaching and research institutions in France or abroad, or from public or private research centers.
L'archive ouverte pluridisciplinaire HAL, est destinée au dépôt et à la diffusion de documents scientifiques de niveau recherche, publiés ou non, émanant des établissements d'enseignement et de recherche français ou étrangers, des laboratoires publics ou privés. 


\section{Accepted Manuscript}

Title: A conditioned reinforcer did not help to maintain an operant conditioning in the absence of a primary reinforcer in horses

Authors: Léa Lansade, Ludovic Calandreau

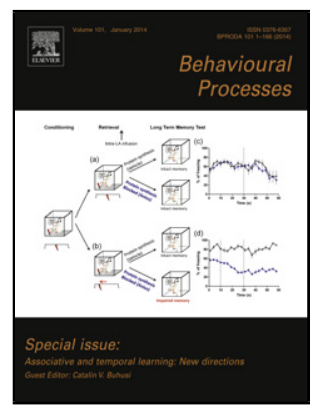

PII:

S0376-6357(17)30219-X

DOI: https://doi.org/10.1016/j.beproc.2017.11.012

Reference: BEPROC 3545

To appear in:

Behavioural Processes

Received date:

$12-5-2017$

Revised date:

25-10-2017

Accepted date:

$16-11-2017$

Please cite this article as: Lansade, Léa, Calandreau, Ludovic, A conditioned reinforcer did not help to maintain an operant conditioning in the absence of a primary reinforcer in horses.Behavioural Processes https://doi.org/10.1016/j.beproc.2017.11.012

This is a PDF file of an unedited manuscript that has been accepted for publication. As a service to our customers we are providing this early version of the manuscript. The manuscript will undergo copyediting, typesetting, and review of the resulting proof before it is published in its final form. Please note that during the production process errors may be discovered which could affect the content, and all legal disclaimers that apply to the journal pertain. 


\section{A conditioned reinforcer did not help to maintain an operant conditioning in the absence of a} primary reinforcer in horses

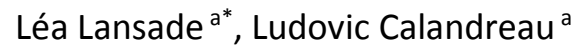

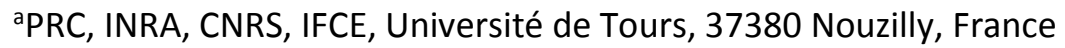

*corresponding author

Mail: lea.lansade@inra.fr

\section{HIGHLIGHTS}

- Pavlovian associations between food and the word 'good' were conducted (288 times)

- In theory, this word could thus serve as a conditioned reinforcer (CR)

- The CR was used instead of food during an operant task

- In the absence of food, horses did not respond more with the CR than without

- The CR was ineffective to maintain a conditioned response in the absence of food

\section{Abstract}

The use of conditioned reinforcers is increasingly promoted in animal training. Surprisingly, the efficiency of their use remains to be demonstrated in horses. This study aimed to determine whether an auditory signal which had previously been associated with a food reward 288 times could be used as a conditioned reinforcer to replace the primary reinforcer in an unrelated operant conditioning procedure. Fourteen horses were divided into two groups of 7: No Reinforcement (NR) and Conditioned Reinforcement (CR). All horses underwent nine sessions of Pavlovian conditioning during which the word "good" was associated with food (32 associations/ session). The horses then followed five sessions of operant conditioning ( 30 trials/ session) during which they had to touch a cone signaled by an experimenter to receive a food reward. The last day, horses underwent one test session of the 
operant response: no reward was given, but the word "good" was said each time a CR horse touched the cone. Nothing was said in the NR group. CR horses did not achieve more correct trials than NR horses during the test. These findings again show that the conditioned reinforcement was ineffective when used instead of the primary reinforcement to maintain conditioning.

Keywords: secondary reinforcement; instrumental conditioning; Pavlovian conditioning; equus caballus; training 


\section{Introduction}

Conditioned reinforcement, also called secondary reinforcement is widely used by animal trainers (Feng et al., 2016). It consists in associating a stimulus (e.g. a word, a sound, a stroke) with a primary reinforcer, generally a food reward. After a certain number of Pavlovian associations between the stimulus and the primary reinforcer (the Unconditioned Stimulus, US), it becomes a "Conditionned Stimulus-CS" (Skinner, 1938; Bugelski, 1938). The CS can thus be used in two ways at least. The first is to use it during the acquisition phase to improve learning. In this case, it is applied simultaneously with the primary food reinforcer and then animals are tested to see if they learn faster than those given the food alone (e.g. Langbein et al., 2007). The second is to replace the primary reinforcer with the CS and subjects are tested to see if they continue to complete the task, that is to say that it increases resistance to extinction. In this paper, we focused on this second question. The efficacy of a CR to increase resistance to extinction has been proved in species such as rodents and dogs (Smith and Davis, 2008; Crombag et al., 2008; Urushihara, 2004). However surprisingly, while this technique is increasingly promoted in the horse industry, when riders use a CS to replace the stimuli used in the initial stages of training (Baragli et al., 2015), its efficiency remains to be demonstrated scientifically. Two previous studies tested its efficacy in extinction in horses, but no effect was found (McCall and Burgin, 2002; Williams et al., 2004). Among the different parameters that could explain this absence of effect, one is the number of associations between the US (e.g. food) and the CS (e.g. a sound). Indeed, in these two experiments, the number of associations was less than a hundred. Thus, it was postulated that a larger number of associations could improve the efficacy of the conditioned reinforcer.

The aim of this study was to investigate whether an auditory signal previously associated repeatedly with a food reward (288 times) could be used as a conditioned reinforcer to substitute the primary reinforcer, in other words to increase resistance to extinction. To this end, horses were first trained to complete an operant task with a food reward. Once the task had been learnt, instead of the food reward, we used the conditioned reinforcer. The purpose was to determine whether horses continued responding to the operant task longer when the conditioned reinforcer was used. 


\section{Material and methods}

\subsection{Animals and groups}

This study was conducted on 14 one-year old saddle horses randomly divided into two groups of seven: No Reinforcement "NR" (five females and two males) and Conditioned Reinforcement "CR" (four females and three males). They were accustomed to being handled and haltered. They had lived at pasture altogether (except during the three months of winter) until the beginning of the experiment. During the five weeks of the study (W1 to W5), for five days per week they were housed individually in an inside loose box with wood shavings $(6 \mathrm{~m} \times 3 \mathrm{~m})$ with an adjacent outside area $(3 \mathrm{~m} \times 3 \mathrm{~m})$ for four hours per day. They spent the rest of the time together at pasture. A feed bucket was attached to the door of each box. This door consisted of metal bars. Water and hay were available ad libitum. No feed restriction was imposed.

\subsection{Training}

Throughout training, each horse was tested in its own loose box. In order to reduce the stress induced by social isolation, a familiar "audience horse" was placed in the box facing the horse, clearly visible. The other horses were kept in their outside areas and could not see the tested horse. The horse to be tested was led by a handler from the outside area to its box, where the test began immediately. The horse could move freely in its box during the session. An experimenter sat two meters (Pavlovian) or one meter (operant) in front of the door, visible to the horse. He stayed motionless; his gaze was fixed and looking in front of him. The experiment lasted 5 weeks and was composed of three phases: acquisition of Pavlovian conditioning, acquisition of operant conditioning and a test session during which the food reward was absent, but the conditioned reinforcer was used in the CR group. The first two phases were identical for the two groups, while the third differed. The procedures of conditioning were similar to those used with success in Lansade et al. (2013), except for the nature and the length of the CS. The experimenter had limited interaction with the horses outside the experiments and both groups were managed and handled in exactly the same manner. 


\subsubsection{Acquisition of Pavlovian conditioning}

The purpose was to associate an auditory stimulus with placing food in a feed bucket. The auditory stimulus was the word "good" pronounced slowly by the experimenter; this was the CS. A handful of pellets was distributed immediately at the end of the CS presentation. Nine sessions of Pavlovian conditioning were conducted for each horse: once daily for the first five days and once weekly for the next four weeks. Each session lasted 32 min, during which 32 associations between the CS and the distribution of pellets were carried out. Within a session, the length between two associations varied from $30 \mathrm{sec}$ to three min (average: one minute) and was randomly determined according to a predetermined schedule (the same for all horses). By the end of the Pavlovian conditioning, a total of 288 associations between the word "good" and the food had been completed for each horse.

\subsubsection{Acquisition of operant conditioning}

The box was equipped with two orange and white traffic cones (60 cm high) fixed on both sides of the feed bucket. The purpose of the operant conditioning was to teach the horse to touch one of the two cones as signaled by the experimenter in order to obtain a reward (pellets). To give the signal, the experimenter tapped the top of the cone associated with the reward with her finger for a maximum of $15 \mathrm{~s}$ or until the horse touched any part of it with its nose. When a trial began, the experimenter gave the signal to the horse. If the horse did not touch a cone within $15 \mathrm{~s}$, an additional $10 \mathrm{~s}$ were allowed to attract the horse and help it to touch the cone (with pellets or by guiding it with a halter). Immediately after the horse had touched the cone indicated, a small handful of pellets was put in the feed bucket. Touching the other cone was not rewarded. The next trial began $10 \mathrm{~s}$ after the horse had swallowed the pellets and removed its nose from the feed bucket. Each session consisted in 30 consecutive trials. The experimenter pointed to the right and left cones 15 times each, in a random order. Horses completed five daily sessions of acquisition during week five. The number of times the horse touched the cone indicated within $15 \mathrm{sec}$ or less (i.e. successful trials) during each session was recorded. 


\subsubsection{Test session: substitution of the food reward by the conditioned reinforcer in the CR group}

The test session was carried out the day after the last session of acquisition of operant conditioning. The aim was to substitute the primary reward with the conditioned reinforcement in the CR group and to compare the performance of this group with the NR group which had no reinforcement at all (i.e. condition of extinction). The apparatus and procedure used were the same as those described for the operant conditioning, but no food was delivered during the session. However, when an animal from the CR group touched the cone, it immediately heard the word "good". Nothing occurred when an animal from the NR group touched the cone. The experimenter looked straight ahead and stayed motionless until the next trial. The number of successful trials was recorded during this session.

\subsection{Statistical Analyses}

Non-parametric statistics were used to compare the number of successful trials in operant conditioning. Mann-Whitney tests were used for inter-group comparisons. Wilcoxon signed rank tests or Friedman tests were used to compare the number of successful trials between sessions. Two tailed tests were carried out. Statistical significance was calculated according to a threshold of $5 \%$. Statistics were performed with XIstat software.

\section{Results}

During the five acquisition sessions of operant conditioning, the number of successful trials increased significantly in both groups (Friedman test, $C R: Q=15.82 ; P=0.003 ; N R: Q=12.03 ; P=0.017$, Fig.1). As expected, this number did not differ between the two groups during these five acquisition sessions, when the protocol was exactly the same between groups (Mann-Whitney tests, Fig. 1). However, contrary to our expectation, the number of successful trials decreased drastically between $A 5$ and the test session, whatever the group (paired Wilcoxon test, $C R: V=28 ; P=0.022 ; N R$ : V=28; $P=0.022$ ). Moreover, the number of successful trials during the test session did not differ between the CR and NR horses (mean \pm se: $C R, 9.28 \pm 1.68 ; N R, 8.57 \pm 1.38$; Mann-Whitney tests, $U=26.5 ; P=0.85$ ). 


\section{Discussion}

Despite a total of 288 associations between the CS (the word "good") and the US (food), this study did not demonstrate that conditioned reinforcement $(C R)$ was effective in helping maintain the success rate when the food reward was omitted. The efficacy of the CR was not improved by increasing the number of associations compared to previous studies (McCall and Burgin, 2002; Williams et al., 2004). Horses might require an even greater number of associations between the CS and the US than used in this study. However, the number of CS-US associations carried out here was exactly the same as those used in a previous study in horses (Lansade et al., 2013), and this number was sufficient to induce a Pavlovian conditioning, and to reveal another phenomenon, called "Pavlovian to Instrumental Transfer". Moreover, under real conditions it is unlikely that trainers would have the patience to use more associations than tested here. Our results thus again question the usefulness of this common practice in horse training. This does not challenge the principle of $C R$, supported in the scientific literature since the work of Skinner (1938) and including recent research (e.g. Prevel et al., 2016). Nevertheless, it is necessary to determine the exact conditions under which CR is effective in horses. Several factors could be investigated. The first involves the stimulus used. Our study may have failed to show the efficacy of conditioned reinforcement because the horse was unable to identify the relevance of the word ("good"). However, it should be noted that previous studies cited used a clicker or buzz type sound and also failed to show any efficacy (McCall and Burgin, 2002; Williams et al., 2004). Timing is also probably fundamental, but even when manipulating this parameter McCall's study did not reveal any efficacy. Finally, it could be interesting to test the duration of the CR. For example, studies in rodents used CRs lasting for 10s, which is longer than that used in horses to date (Crombag et al., 2008).

To conclude, like previous studies this work did not demonstrate any efficacy of conditioned reinforcement in slowing extinction in horses. Without challenging its existence, it shows that CR is not easy to install in horses and that further studies are required to determine the parameters (type, timing, duration of unconditioned stimulus, etc.) that could render it operational. In the future, it 
would be also interesting to test the efficacy of conditioned reinforcement not to replace the primary reward as we did here, but to enhance the acquisition process when the primary reward is associated with the conditioned reinforcement.

\section{Acknowledgments}

We would like to thank Sue Edrich from the translation agency Interconnect for correcting the English manuscript. IFCE funded this experiment. This funding source had no role in study design, data collection or analysis, or preparation or submission of the manuscript.

\section{References}

Baragli, P., Padalino, B., and Telatin, A. 2015. The role of associative and non-associative learning in the training of horses and implications for the welfare (a review). Annali dell'Istituto Superiore di Sanità, 51(1), 40-51.

Bugelski, R. 1938. Extinction with and without sub-goal reinforcement. Journal of Comparative Psychology, 26: 121-134.

Crombag, H.S., Galarce, E.M. and Holland, P.C. 2008. Pavlovian influences on goal-directed behavior in mice: The role of cue-reinforcer relations. Learning \& Memory, 15: 299-303.

Feng, L.C., Howell, T.J. and Bennett, P.C. 2016. How clicker training works: Comparing Reinforcing, Marking, and Bridging Hypotheses. Applied Animal Behaviour Science, 181: 34-40.

Langbein, J., Siebert, K., Nuernberg, G., and Manteuffel, G., 2007. The impact of acoustical secondary reinforcement during shape discrimination learning of dwarf goats (Capra hircus). Applied Animal Behaviour Science, 103, 35-44. Lansade, L., Coutureau, E., Marchand, A., Baranger, G., Valenchon, M. and Calandreau, L. 2013. Dimensions of Temperament Modulate CueControlled Behavior: A Study on Pavlovian to Instrumental Transfer in Horses (Equus Caballus). PLoS ONE, 8: e64853.

McCall, C.A. and Burgin, S.E. 2002. Equine utilization of secondary reinforcement during response extinction and acquisition. Applied Animal Behaviour Science, 78: 253-262.

Prevel, A., Riviere, V., Darcheville, J.C. and Urcelay, G.P. 2016. Conditioned reinforcement and backward association. Learning and Motivation, 56: 38-47.

Skinner, B.F. 1938. The Behavior of Organisms: An Experimental Analysis. Appleton-Century, Oxford, England

Smith, S.M. and Davis, E.S. 2008. Clicker increases resistance to extinction but does not decrease training time of a simple operant task in domestic dogs (Canis familiaris). Applied Animal Behaviour Science, 110: 318-329.

Urushihara, K. 2004. Excitatory backward conditioning in an appetitive conditioned reinforcement preparation with rats. Behavioural Processes, 67: 477-489. 
Williams, J.L., Friend, T.H., Nevill, C.H. and Archer, G. 2004. The efficacy of a secondary reinforcer (clicker) during acquisition and extinction of an operant task in horses. Applied Animal Behaviour Science, 88: 331-341. 
Figure 1: Successful trials (mean \pm se) performed per session of operant conditioning ( 30 trials/ session).

The procedure was exactly the same for both groups in acquisition, but differed in the test session.

NS: non-significant, inter-group comparisons (Mann-Whitney test: $U_{A 1}=23.5, P=0.95 ; U_{A 2}=25.5, P=0.95 ; \quad U_{A 3}=30, P=0.52$;

$U_{A 4}=20, P=0.61 ; U_{A 5}=17.5, P=0.40 ; U_{\text {extinction }}=26.5, P=0.85$ )

A1-A5: Sessions 1 to 5 of acquisition of operant conditioning

Test session: Session of operant conditioning during which no food was delivered

NR: No reinforcer was used during the test session, $N=7$

CR: A conditioned reinforcer was used during the test session, $\mathrm{N}=7$

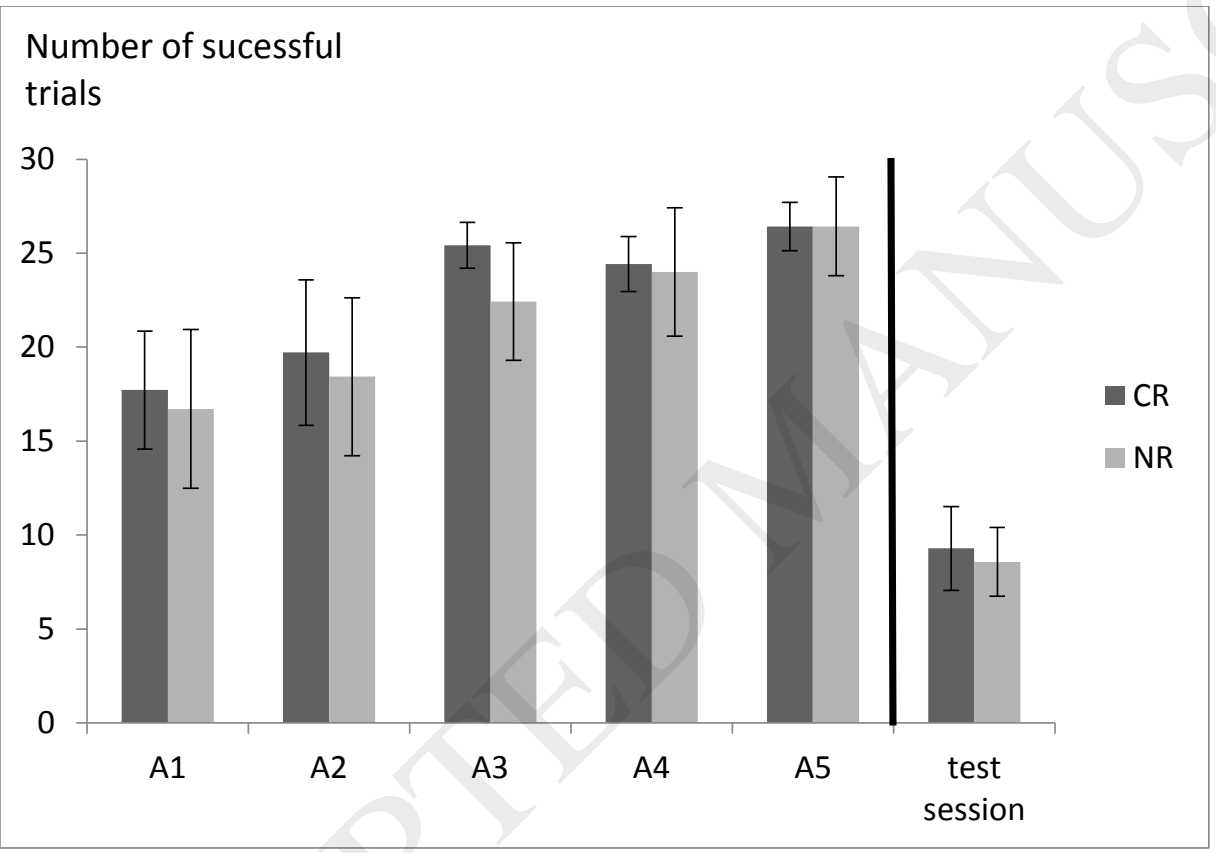

